\title{
Graph Algorithms and Applications 2
}

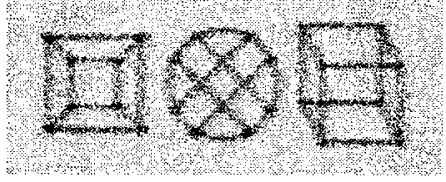


This page is intentionally left blank 


\section{Graph Algorithms and Applications 2}

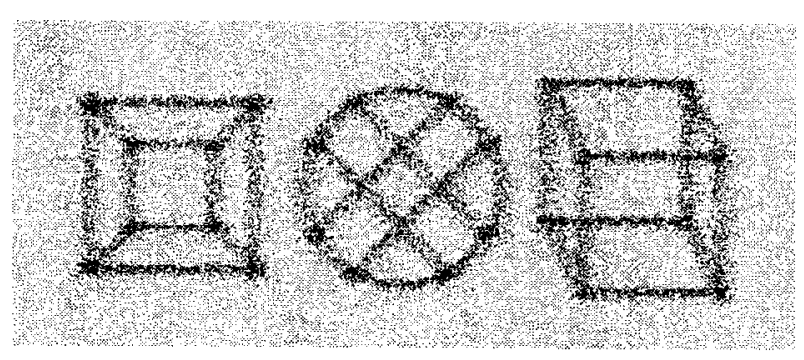

EDITORS

Giuseppe Liotta University of Perugia, Italy

Roberto Tamassia

Brown University, USA

Ioannis G Tollis

University of Crete - ICS-FORTH, Greece, and The University of Texas at Dallas, USA

\section{Noworld Scientific}

NEW JERSEY - LONDON • SINGAPORE - BEIJING - SHANGHAI - HONG KONG - TAIPEI - CHENNAI 


\section{Published by}

World Scientific Publishing Co. Pte. Ltd.

5 Toh Tuck Link, Singapore 596224

USA office: Suite 202, 1060 Main Street, River Edge, NJ 07661

UK office: 57 Shelton Street, Covent Garden, London WC2H 9HE

\section{British Library Cataloguing-in-Publication Data}

A catalogue record for this book is available from the British Library.

\section{GRAPH ALGORITHMS AND APPLICATIONS 2}

Copyright (C) 2004 by World Scientific Publishing Co. Pte. Ltd.

All rights reserved. This book, or parts thereof, may not be reproduced in any form or by any means, electronic or mechanical, including photocopying, recording or any information storage and retrieval system now known or to be invented, without written permission from the Publisher.

For photocopying of material in this volume, please pay a copying fee through the Copyright Clearance Center, Inc., 222 Rosewood Drive, Danvers, MA 01923, USA. In this case permission to photocopy is not required from the publisher.

ISBN $981-238-855-9(\mathrm{pbk})$

Printed in Singapore. 


\section{Preface}

This book contains volumes 4-5 of the Journal of Graph Algorithms and Applications (JGAA). Topics of interest for $J G A A$ include:

Design and analysis of graph algorithms: exact and approximation graph algorithms; centralized and distributed graph algorithms; static and dynamic graph algorithms; internal- and external-memory graph algorithms; sequential and parallel graph algorithms; deterministic and randomized graph algorithms.

Experiences with graph algorithms: animations; experimentations; implementations.

Applications of graph algorithms: computational biology; computational geometry; computer graphics; computer-aided design; computer and interconnection networks; constraint systems; databases; graph drawing; graph embedding and layout; knowledge representation; multimedia; software engineering; telecommunication networks; user interfaces and visualization; VLSI circuits.

$J G A A$ is supported by distinguished advisory and editorial boards, has high scientific standards, and takes advantage of current electronic document technology. The electronic version of $J G A A$ is available on the Web at

$$
\text { http://jgaa.info/ }
$$

We would like to express our gratitude to the members of the advisory board for their encouragement and support of the journal, to the members of the editorial board and guest editors for their invaluable service and to the many anonymous referees for their essential role in the selection process. Finally, we would like to thank all the authors who have submitted papers to JGAA.

Giuseppe Liotta Roberto Tamassia Ioannis G. Tollis 
This page is intentionally left blank 


\section{Journal of Graph Algorithms and Applications}

\section{Managing Editor:}

Giuseppe Liotta, University of Perugia

\section{Editors-in-Chief:}

Roberto Tamassia, Brown University

Ioannis G. Tollis, University of Crete-ICS-FORTH, Greece, and The University of Texas at Dallas, USA

\section{Advisory Board:}

I. Chlamtac, University of Texas at Dallas

S. Even, Technion

G. N. Frederickson, Purdue University

T. C. Hu, University of California at San Diego

D. E. Knuth, Stanford University

C. L. Liu, University of Illinois

K. Mehlhorn, Max-Planck-Institut für Informatik

T. Nishizeki, Tohoku University

F. P. Preparata, Brown University

I. H. Sudborough, University of Texas at Dallas

R. E. Tarjan, Princeton University

M. Yannakakis, Stanford University

\section{Editorial Board:}

G. Di Battista, University of Roma Tre

$P$. Eades, University of Sydney

D. Eppstein, University of California at Irvine

M. Fürer, Pennsylvania State University

A. Gibbons, King's College

M. T. Goodrich, University of California at Irvine

$X$. He, State University of New York at Buffalo

A. Itai, Technion

Y. Kajitani, University of Kitakyushu

M. Kaufmann, Universität Tübingen

$S$. Khuller, University of Maryland

E. W. Mayr, Technischen Universität München

J. S. B. Mitchell, State University of New York at Stony Brook

B. Raghavachari, University of Texas at Dallas

D. Wagner, University of Karlsruhe

T. Warnow, University of Texas at Austin 
This page is intentionally left blank 


\section{Contents}

Volume 4:1 (2000)

Approximations of Weighted Independent Set and Hereditary Subset

Problems. Magnús M. Halldórsson. Communicated by Samir

Khuller. . . . . . . . . . . . . . . . . . .

\section{Volume 4:2 (2000)}

Approximation Algorithms for Some Graph Partitioning Problems.

G. He, J. Liu and C. Zhao. Communicated by David Eppstein. .

\section{Volume 4:3 (2000)}

\section{Special Issue on Selected Papers from the 1998 Symposium on Graph Drawing. Guest Editors: Giuseppe Liotta and Sue $H$. Whitesides.}

Guest Editors' Foreword. Giuseppe Liotta and Sue H. Whitesides. . .

Geometric Thickness of Complete Graphs. Michael B. Dillencourt, David Eppstein and Daniel S. Hirschberg. Communicated by Giuseppe Liotta and Sue H. Whitesides.

Balanced Aspect Ratio Trees and Their Use for Drawing Large Graphs. Christian A. Duncan, Michael T. Goodrich and Stephen G. Kobourov. Communicated by Giuseppe Liotta and Sue H. Whitesides.

Difference Metrics for Interactive Orthogonal Graph Drawing Algorithms. Stina Bridgeman and Roberto Tamassia. Communicated by Giuseppe Liotta and Sue H. Whitesides. . . . . . . . . . . . .

Techniques for the Refinement of Orthogonal Graph Drawings. Janet M. Six, Konstantinos G. Kakoulis and Ioannis G. Tollis. Communicated by Giuseppe Liotta and Sue H. Whitesides. . . . . . . 109

A Split \& Push Approach to 3D Orthogonal Drawing. Giuseppe Di Battista, Maurizio Patrignani and Francesco Vargiu. Communicated by Giuseppe Liotta and Sue H. Whitesides. . . . . . . . . . 139

Using Graph Layout to Visualize Train Interconnection Data. Ulrik Brandes and Dorothea Wagner. Communicated by Giuseppe Liotta and Sue H. Whitesides. . . . . . . . . . . . . . . . . . . 169

Navigating Clustered Graphs Using Force-Directed Methods. Peter Eades and Mao Lin Huang. Communicated by Giuseppe Liotta and Sue $\mathrm{H}$. Whitesides.

Dynamic WWW Structures in 3D. Ulrik Brandes, Vanessa Kääb, Andres Löh, Dorothea Wagner and Thomas Willhalm. Communicated by Giuseppe Liotta and Sue H. Whitesides. . . . . . . . . . 21 
Clustering in Trees: Optimizing Cluster Sizes and Number of Subtrees.

Susanne E. Hambrusch, Chuan-Ming Liu and Hyeong-Seok Lim.

Communicated by Giuseppe Liotta. . . . . . . . . . . . . . . . . 229

Volume 5:1 (2001)

Planarizing Graphs - A Survey and Annotated Bibliography. Annegret Liebers. Communicated by Alan Gibbons. . . . . . . . . . . 257

Volume 5:2 (2001)

Fully Dynamic 3-Dimensional Orthogonal Graph Drawing. M. Closson, S. Gartshore, J. Johansen and S. K. Wismath. Communicated by Dorothea Wagner.

Volume 5:3 (2001)

1-Bend 3-D Orthogonal Box-Drawings: Two Open Problems Solved.

Therese Biedl. Communicated by Giuseppe Liotta. . . . . . . . . 369

Volume 5:4 (2001)

Computing an Optimal Orientation of a Balanced Decomposition Tree for Linear Arrangement Problems. Reuven Bar-Yehuda, Guy Even, Jon Feldman and Joseph (Seffi) Naor. Communicated by Tandy Warnow. . . . . . . . . . . . . . . . . . . 38

Volume 5:5 (2001)

Special Issue on Selected Papers from the 1998 Dagstuhl Seminar on Graph Algorithms and Applications. Guest Editors: Takao Nishizeki, Roberto Tamassia and Dorothea Wagner.

Guest Editors' Foreword. Takao Nishizeki, Roberto Tamassia and Dorothea Wagner. . . . . . . . . . . . . . . . . . . . 417

Carrying Umbrellas: An Online Relocation Game on a Graph. Jae- $\mathrm{Ha}$ Lee, Chong-Dae Park and Kyung-Yong Chwa. Communicated by Takao Nishizeki, Roberto Tamassia and Dorothea Wagner. . . . . 419

New Bounds for Oblivious Mesh Routing. Kazuo Iwama, Yahiko Kambayashi and Eiji Miyano. Communicated by Takao Nishizeki, Roberto Tamassia and Dorothea Wagner. 
Finding All the Best Swaps of a Minimum Diameter Spanning Tree Under Transient Edge Failures. Enrico Nardelli, Guido Proietti and Peter Widmayer. Communicated by Takao Nishizeki, Roberto Tamassia and Dorothea Wagner. . . . . . . . . . . . . . 455

Shelling Hexahedral Complexes for Mesh Generation. Matthias MüllerHannemann. Communicated by Takao Nishizeki, Roberto Tamassia and Dorothea Wagner. . . . . . . . . . . . . . . . 475

Connectivity of Planar Graphs. Hubert de Fraysseix and Patrice Ossona de Mendez. Communicated by Takao Nishizeki, Roberto Tamassia and Dorothea Wagner. . . . . . . . . . . . . . 509 